\title{
The Impact of Multidisciplinary Care in a Large Volume Robot-Assisted Radical Prostatectomy Program: A Paradoxical Stage Migration toward More Aggressive Disease
}

Jospeh F. Renzulli II*, Michael M. Maddox, Omar Nadeem, Simone Thavaseelan, Gyan Pareek, Anthony E. Mega

Warren Alpert Medical School, Brown University, Providence, USA

Email: ${ }^{*}$ jrenzulli@lifespan.org

Received 22 September 2014; revised 21 October 2014; accepted 25 November 2014

Copyright (C) 2014 by authors and Scientific Research Publishing Inc.

This work is licensed under the Creative Commons Attribution International License (CC BY).

http://creativecommons.org/licenses/by/4.0/

(c) (i) Open Access

\section{Abstract}

Introduction: With the widespread use of robot-assisted radical prostatectomy (RARP), a stage migration to less aggressive prostate cancer (CaP) may be expected in pathological specimens due to over-treatment of low risk disease. It is unclear whether implementation of a multidisciplinary clinic (MDC) model would offset this phenomenon. We sought to analyze our database for possible stage migration in prostatectomy specimens in the setting of MDC. Methods: A total of 262 patients who underwent open prostatectomy (OP) from 2004 to 2006 and 757 patients who underwent RARP from 2007 to 2011 were identified from our prospective database. The implementation of MDC occurred concurrently at the time of RARP initiation. Demographic data, pathology, positive margin rates along with standard CaP reporting data were recorded. The two groups were compared with regards to percentage of cases stratified by Gleason grade. Results: The number of CaP cases managed at our institution increased considerably after the introduction of robotics and MDC. There was a significant decrease in the patients with Gleason 6 CaP undergoing RARP as compared with OP $(p=0.001)$. Additionally, RARP was performed on a significantly greater percentage of Gleason 7 disease $(p<0.001)$. When comparing pathological stage, there was a significant increase in the incidence of pT3 disease following RARP $(p<0.0001)$. Conclusions: The introduction of a MDC and minimally invasive radical prostatectomy did not result in an increased application of surgery for the treatment of low risk prostate cancer. This highlights the importance of MDC in a large volume RARP program.

\footnotetext{
"Corresponding author.

How to cite this paper: Renzulli II, J.F., Maddox, M.M., Nadeem, O., Thavaseelan, S., Pareek, G. and Mega, A.E. (2014) The Impact of Multidisciplinary Care in a Large Volume Robot-Assisted Radical Prostatectomy Program: A Paradoxical Stage Migration toward More Aggressive Disease. Open Journal of Internal Medicine, 4, 108-114.
} 


\section{Keywords}

\section{Prostate Cancer, Robotics, Multidisciplinary Care}

\section{Introduction}

Prostate cancer has evolved in regards to the diagnosis, medical management and surgical treatment of the disease. The American Cancer Society estimates that a total of 2.8 million men in the United States have prostate cancer, with 241,740 new cases diagnosed in 2012 [1]. However, controversy remains regarding the utility of a screening program and whether primary interventions for prostate cancer offer any benefit to the patients.

Autopsy studies have shown that the incidence of prostate cancer in men over 50 years of age is approximately $40 \%$, but the lifetime risk of clinically detected cancer in American men is only $10 \%$ [2]. This obviates the discrepancy between the diagnosis and clinical relevance of some prostate cancers, which is the basis of the contemporary prostate cancer debate. Large screening trials, particularly the Prostate, Lung, Colorectal and Ovarian screening trial and The European Randomized Study of Screening for Prostate Cancer, have reported conflicting results of the utility of prostate cancer screening [3] [4]. However, many believe that this is a result of the application of aggressive treatment to patients with less aggressive disease biology. With this in mind, many have questioned the routine practice of prostate specific antigen (PSA) screening. The United States Preventive Services Task Force (USPSTF) recently repudiated PSA screening with a grade "D" recommendation for its effectiveness as a screening test. The PIVOT trial confirmed the lack of survival benefit of radical prostatectomy for Gleason 6 prostate cancer compared with observation, while suggesting a benefit of treatment in a higher risk population [5]. Furthermore, the availability of minimally invasive treatment options, including RARP, potentially exacerbates the problem of overtreatment of prostate cancer [6] [7].

Management of prostate cancer encompasses numerous specialties which include surgery, radiation therapy and medical oncology. Multidisciplinary clinic (MDC) models are rapidly evolving in management of various malignancies and have been well-received from perspectives of both the provider and the patient [8]. MDC provides opportunity for increased physician collaboration, which in turn reduces bias and increases patient satisfaction [8]-[10]. MDC model in prostate cancer has also led to higher selection of active surveillance of men with low risk prostate cancer in one cohort of patients [11]. Therefore, we investigated the introduction of a minimally invasive robotic prostatectomy program and the impact of MDC in treatment of low risk prostate cancer patients.

\section{Materials and Methods}

We reviewed the prostate cancer tumor registry to assess for any trends in the number of patients referred to our institution with prostate cancer. We deduced the impact of robotics on the referral pattern to our facility by comparing the number of referrals both before and after the implementation of robotic prostatectomy in 2007. We recounted our experience with radical prostatectomy (RP) over an eight year period between 2004 and 2011, during which a robotic surgery program and MDC was initiated in 2007. Since 2007 every patient with prostate cancer was offered an appointment in the MDC. During the visit, the patient had a discussion with a medical oncologist, radiation oncologist and urologist about primary treatment options for his prostate cancer. If the patient had very low risk prostate cancer (T1c or T2a, Gleason Score 6, PSA $<10 \mathrm{ng} / \mathrm{ml}$, less than 4 cores positive, and maximum core positive $<50 \%$ ) then a consensus recommendation of active surveillance was presented as the preferred management option.

A total of 262 patients who underwent OP from 2004 to 2006 and 757 patients undergoing RARP between 2007 and 2011 were identified from an IRB approved database. De-identified pathology reports were retrospectively reviewed for the OP cohort, while the robotic patient data were prospectively collected by an independent third party. Demographic data, operative details, pathology, positive margin status, and perioperative complications were monitored.

The surgical pathology was determined by multiple pathologists within the department of pathology at Brown University for both the open and robotic prostatectomy specimens. The percentage of cases performed stratified by pathologic Gleason grades were compared between the OP and RARP groups. In addition, pathologic tumor 
(T) stages were reviewed and analyzed for any significant difference to suggest a stage migration. Statistical analysis was performed utilizing two-proportion z-tests to delineate statistically significant differences between the two populations.

\section{Results}

The overall trend in prostate cancer referrals to our institution is displayed in Figure 1. The number of cases of prostate cancer fell from 2000 to 2004 by 49\% before rising modestly between 2004 and 2006. In 2007, there was an increase from 81 to 218 cases after the acquisition of a Da Vinci ${ }^{\mathrm{TM}}$ robot. Subsequent operative cases continued to rise in 2008 until a plateau was achieved in 2009 at 274 cases, highlighting a considerable increase in the number of cases managed at our facility with the onset of robotic surgery. The overall percentage of patients in the state with prostate cancer being managed at our institution, which is the only center in which RARP is performed, is consistent with the national average for the proportion of prostate cancer cases managed at a teaching-institution as well as the sharp reduction seen in prostatectomy volume for hospitals without a Da Vin$\mathrm{ci}^{\mathrm{TM}}$ system [12].

Recognizing that an influx of patients with prostate cancer referred to a robotics center may lead to increased surgical treatment of indolent disease, we compared the pathologic findings between our open and robotic prostatectomy cohorts. The distribution of Gleason grades in the OP group were $52.3 \%$ and $40.9 \%$ with pathologic Gleason grades of 6 and 7 respectively. This contrasts with the 32.6\% and $61.2 \%$ of robotic patients having Gleason score 6 and 7 disease respectively. This represents a statistically significant difference in the proportion of Gleason 6 and Gleason 7 disease between the two groups $(p=0.001, p<0.001)$.

Due to known inter-observer variability and subjectivity associated with Gleason grading amongst pathologists, we compared the pathologic stages (pT2 versus pT3) of the two surgical approaches for each patient. For the open prostatectomy cohort, pT2 and pT3 represented $86.8 \%$ and $10.7 \%$ of the overall group respectively. The robotic patients exhibited an incidence of $75.6 \%$ pT2 and $24.4 \%$ pT3 disease $(\mathrm{p}=0.0001$ and $<0.0001)$. This confirms a statistically significant difference with respects to pathologic measure of disease severity, as gauged in this study by Gleason grade and stage. These are seen in Table 1 and Figure 2.

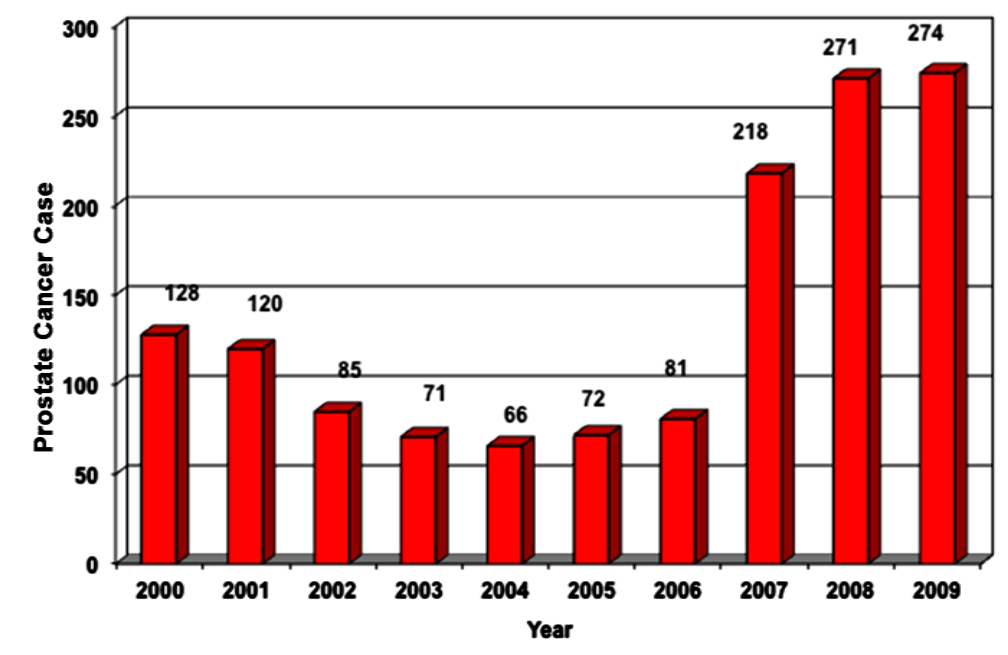

Figure 1. Institutional trend in prostate cancer case referrals.

Table 1. Gleason grade comparison by surgical approach.

\begin{tabular}{|c|c|c|c|}
\hline & RARP & $\mathrm{OP}$ & Statistical Significance \\
\hline Gleason 6 & $32.6 \%$ & $52.3 \%$ & $\mathrm{p}=0.0001$ \\
\hline Gleason 7 & $61.2 \%$ & $40.9 \%$ & $\mathrm{p}<0.0001$ \\
\hline Gleason 8 & $3.5 \%$ & $2.5 \%$ & $\mathrm{p}=0.22$ \\
\hline
\end{tabular}




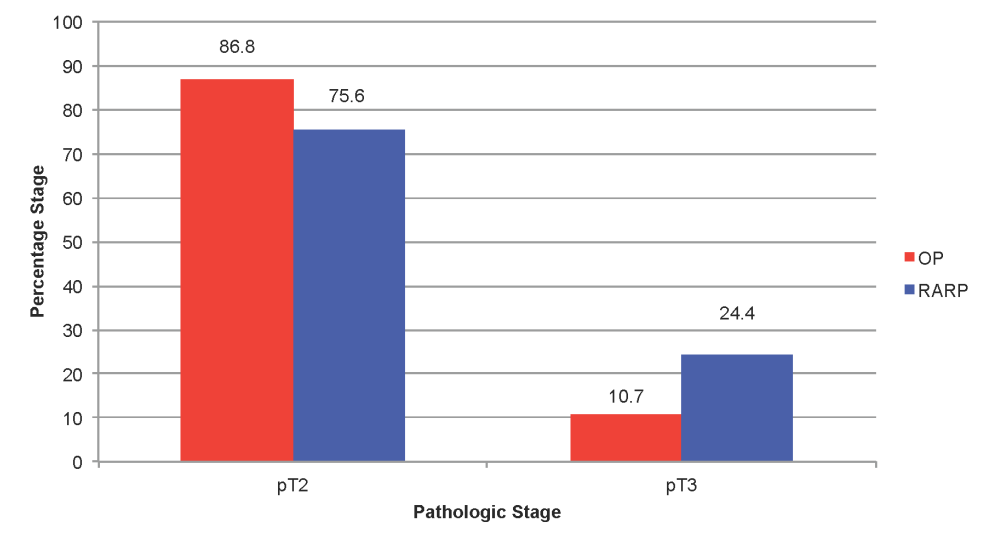

Figure 2. Pathologic stage comparison by surgical approach.

\section{Discussion}

There is concern about the over-detection and subsequent over-treatment of prostate cancer. It is estimated that there is a mean lead-time for diagnosis of $11-12$ years and over detection from population screening of approximately $50 \%$ [13]. Contemporary reports in the literature suggest that in the era of PSA screening, there has been a considerable migration from high risk to low risk prostate cancer. The CaPSURE database has demonstrated that the risk stratification of most prostate cancer cases today has shifted, with an increase in low risk patients from $31.2 \%$ to $47.7 \%$ while high risk patients decreased from $40.9 \%$ to $14.8 \%$ [14]. Similarly, the SEER database exhibits a significant decline in metastatic disease at diagnosis (17.9\% annually) [15]. In addition, there is an increase in the very low risk patient population with prostate cancer evidenced by a decreased age, PSA, and percentage of positive biopsies [16].

Given this widespread decrease in risk of the index prostate cancer patient, one might expect an adoption of a less aggressive treatment approach. However, Harlan et al. noted a decreased utilization of watchful waiting in the low risk group of patients from $18.9 \%$ to $7.2 \%$ between years 1992 to 1994 compared to years 1998 to 2000 , respectively [17]. Many reports have documented a concomitant increase in the utilization of radical prostatectomy as primary therapy with up to $60 \%$ of patients with low risk characteristics undergoing surgery [16] [18] [19].

With the increased surgical treatment of prostate cancer in the United States along with a declining risk profile, it is intuitive to expect a decrease in pathologic aggressiveness. Jhaveri et al. demonstrated a decrease in extra-capsular extension at final pathology from $81 \%$ to $36 \%$ in over 700 patients treated with radical prostatectomy [20]. Along with a migration to lower pathologic T stage, Moul et al. displayed a more favorable surgical outcome with decreased positive surgical margins and lymph node positivity [21]. Despite these improvements in pre-treatment and pathologic characteristics, there remains a lack of reproducible survival benefits which raises questions about appropriate patient selection.

The PIVOT randomized trial confirmed this lack of survival benefit for the treatment of clinically localized prostate cancer. However, on subset analysis the investigators noticed a survival advantage in those patients with a PSA greater than 10 and a statistical trend in the intermediate risk group [5]. Given this, we reviewed our experience with radical prostatectomy over an eight year period during which a dramatic shift from OP to RARP was realized. We specifically tried to ascertain if the availability of a minimally invasive surgical option increased our application of surgery to lower risk patients. We also simultaneously implemented a MDC model in an attempt to decrease this possibility and to improve decision making.

Comparing Gleason grades between our open and robotic prostatectomy cohorts, we found a significant increase in Gleason 7 disease within the robotic group. There have been multiple criticisms of Gleason grade shifts in the literature suggesting this to be a statistical artifact known as the Will Rogers phenomenon rather than a shift in tumor biology [21] [22]. It is true that contemporary pathologic review of prostate cancer has shifted to a predilection towards assigning higher Gleason grades. Multiple studies have confirmed that on re-grading of prostate biopsies, there is significant upgrading in recent years [22]-[24]. In an editorial, Epstein suggested that Gleason 2 - 4 grades are not reliably reproducible among experts and should therefore be avoided 
altogether to avoid a false sense of indolent disease [25]. Unlike these studies showing Gleason upgrading, the close temporal relationship between our open and robotic experiences would argue that any shift in Gleason grading would affect the two cohorts similarly.

In order to avoid conclusions based on the subjective nature of Gleason grading, we also compared the pathological T stage between the OP and RARP groups. Consistent with the Gleason grading data, we found an increased proportion of pT3 disease among the RARP patients. This confirms a more aggressive disease pathology in our robotic experience as compared to our recent open prostatectomies. Although we don't postulate a significant change in tumor biology over a short period of time in our community, we are reassured that our practice of radical surgery for prostate cancer appropriately reflects the changing philosophy that primary treatment in low risk patients likely does not afford a significant benefit.

We utilized a multidisciplinary assessment of the newly diagnosed prostate cancer patients. All patients diagnosed with prostate cancer discuss therapeutic options with an urologist, a medical oncologist, and a radiation oncologist. It is our judgment that this collaborative care model leads to more effective communication of prognosis and available treatment options to the patients seen in the multidisciplinary approach. In addition, when clinically appropriate, active surveillance is given as consensus recommendation. This may increase the patient's perception and ultimate acceptance of active surveillance for low risk cancers, which has been validated in other cohorts [9]-[11].

Some limitations of our study deserve mention. There was no central pathology review at our institution and may introduce some bias with inter-observer variation. This may be of little significance given the consistent results of Gleason grade and pathologic stage comparisons. In addition, our open prostatectomy database was retrospective whereas the RARP was prospectively collected. However, all prostatectomy specimens in the predefined study period were included limiting any selection bias.

It is also difficult to determine the true, absolute impact of MDC in our study results. While there is little doubt that implementation of MDC led to increased active surveillance rate and stage migration towards more aggressive disease, it is unknown to what degree this would have been different in the absence of simultaneous MDC and RARP initiation. Nevertheless, MDC has a rapidly increasing role in management of newly diagnosed prostate cancer and has been shown to improve decision making and adherence to national guidelines [26].

\section{Conclusion}

Despite a substantial increase in volume of prostate cancer managed at our institution since the adoption of robotic surgery, we have seen a migration toward more aggressive pathology following RARP as compared with a recent OP cohort. This is likely due to an increase in informed decision making through the MDC model. Therefore, a minimally invasive treatment option for prostate cancer has not led to increased primary surgical therapy for indolent prostate cancer at our institution. It highlights the importance of a MDC model in a large volume RARP setting.

\section{Acknowledgements}

None.

\section{Conflicts of Interest}

All authors have no conflicts of interest to report.

\section{References}

[1] Siegel, R., Desantis, C., Virgo, K., et al. (2012) Cancer Treatment and Survivorship Statistics, 2012. CA: A Cancer Journal for Clinicians, 62, 220-241. http://dx.doi.org/10.3322/caac.21149

[2] Menon, M., Parulkar, B. and Baker, S. (1995) Should We Treat Localized Prostate Cancer? An Opinion. Urology, 46, 607-616. http://dx.doi.org/10.1016/S0090-4295(99)80289-1

[3] Schroder, F., Hugosson, J., Roobol, M., et al. (2012) Prostate-Cancer Mortality at 11 Years of Follow-Up. The New England Journal of Medicine, 366, 981-990. http://dx.doi.org/10.1056/NEJMoa1113135

[4] Andriole, G., Crawford, E., Grubb, R., et al. (2012) Prostate Cancer Screening in the Randomized Prostate, Lung, Colorectal, and Ovarian Cancer Screening Trial: Mortality Results after 13 Years of Follow-Up. Journal of the National 
Cancer Institute, 104, 1-8. http://dx.doi.org/10.1093/jnci/djr500

[5] Wilt, T., Brawer, M., Jones, K., et al. (2012) Radical Prostatectomy versus Observation for Localized Prostate Cancer. The New England Journal of Medicine, 367, 203-213. http://dx.doi.org/10.1056/NEJMoa1113162

[6] Barbash, G. and Glied, S. (2010) New Technology and Health Care Costs-The Case of Robot-Assisted Surgery. The New England Journal of Medicine, 363, 701-704. http://dx.doi.org/10.1056/NEJMp1006602

[7] Lowrance, W., Eastham, J., Savage, C., et al. (2012) Contemporary Open and Robotic Prostatectomy Practice Patterns among Urologists in the United States. Journal of Urology, 187, 2087-2093. http://dx.doi.org/10.1016/j.juro.2012.01.061

[8] Litton, G., Kane, D., Clay, G., et al. (2010) Multidisciplinary Cancer Care with a Patient and Physician Satisfaction Focus. Journal of Oncology Practice, 6, e35-e37

[9] Aizer, A.A., Paly, J.J. and Efstathiou, J.A. (2013) Multidisciplinary Care and Management Selection in Prostate Cancer. Seminars in Radiation Oncology, 23, 157-164. http://dx.doi.org/10.1016/j.semradonc.2013.01.001

[10] Gomella, L.G., Lin, J. and Hoffman-Censits, J. (2010) Enhancing Prostate Cancer Care through the Multidisciplinary Clinic Approach: A 15-Year Experience. Journal of Oncology Practice, 6, e5-e10

[11] Aizer, A.A., Paly, J.J., Zietman, A.L., Nguyen, P.L., Beard, C.J., Rao, S.K., et al. (2012) Multidisciplinary Care and Pursuit of Active Surveillance in Low-Risk Prostate Cancer. Journal of Clinical Oncology, 30, 3071-3076. http://dx.doi.org/10.1200/JCO.2012.42.8466

[12] Madeb, R., Golijanin, D., Knopf, J., Kowalczyk, J., Feng, C.Y., Rashid, H., et al. (2011) The Impact of Robotics on Treatment of Localized Prostate Cancer and Resident Education in Rochester, New York. Journal of Endourology, 25, 573-577. http://dx.doi.org/10.1089/end.2010.0498

[13] Draisma, G. and De Koning, H. (2003) MISCAN: Estimating Lead-Time and Over-Detection by Simulation. BJU International, 92, 106-111. http://dx.doi.org/10.1111/j.1464-410X.2003.4409x.x

[14] Cooperberg, M., Lubeck, D., Mehta, S. and Carroll, P.R. (2003) Time Trends in Clinical Risk Stratification for Prostate Cancer: Implications for Outcomes (Data from CaPSURE). Journal of Urology, 170, S21-S27. http://dx.doi.org/10.1097/01.ju.0000095025.03331.c6

[15] Hankey, B., Feuer, E., Clegg, L., Hayes, R.B., Legler, J.M., Prorok, P.C., et al. (1999) Cancer Surveillance Series: Interpreting Trends in Prostate Cancer-Part I: Evidence of the Effects of Screening in Recent Prostate Cancer Incidence, Mortality, and Survival Rates. Journal of the National Cancer Institute, 91, 1017-1024. http://dx.doi.org/10.1093/jnci/91.12.1017

[16] Cooperberg, M., Broering, J., Kantoff, P. and Carroll, P.R. (2007) Contemporary Trends in Low Risk Prostate Cancer: Risk Assessment and Treatment. Journal of Urology, 178, S14-S19. http://dx.doi.org/10.1016/i.juro.2007.03.135

[17] Harlan, S., Cooperberg, M., Elkin, E., Lubeck, D.P., Meng, M.V., Mehta, S.S. and Carroll, P.R. (2003) Time Trends and Characteristics of Men Choosing Watchful Waiting for Initial Treatment of Localized Prostate Cancer: Results from CaPSURE. Journal of Urology, 170, 1804-1807. http://dx.doi.org/10.1097/01.ju.0000091641.34674.11

[18] Stephenson, R. and Stanford, J. (1997) Population-Based Prostate Cancer Trends in the United States: Patterns of Change in the Era of Prostate-Specific Antigen. World Journal of Urology, 15, 331-335. http://dx.doi.org/10.1007/BF01300179

[19] Cooperberg, M., Broering, J. and Carroll, P. (2010) Time Trends and Local Variation in Primary Treatment of Localized Prostate Cancer. Journal of Clinical Oncology, 28, 1117-1123. http://dx.doi.org/10.1200/JCO.2009.26.0133

[20] Jhaveri, F., Klein, E., Kupelian, P., et al. (1999) Declining Rates of Extracapsular Extension after Radical Prostatectomy: Evidence for Continued Stage Migration. Journal of Clinical Oncology, 17, 3167-3172.

[21] Moul, J., Wu, H.Y., Sun, L., McLeod, D.G., Amling, C., Lance, R., et al. (2002) Epidemiology of Radical Prostatectomy for Localized Prostate Cancer in the Era of Prostate-Specific Antigen: An Overview of the Department of Defense Center for Prostate Disease Research National Database. Surgery, 132, 213-219. http://dx.doi.org/10.1067/msy.2002.125315

[22] Albertsen, P., Hanley, J., Barrows, G., Penson, D.F., Kowalczyk, P.D.H., Melinda Sanders, M. and Fine, J. (2005) Prostate Cancer and the Will Rogers Phenomenon. Journal of the National Cancer Institute, 97, 1248-1253. http://dx.doi.org/10.1093/jnci/dji248

[23] Thompson, I., Canby-Hagino, E. and Lucia, M. (2005) Stage Migration and Grade Inflation in Prostate Cancer: Will Rogers Meets Garrison Keillor. Journal of the National Cancer Institute, 97, 1236-1237. http://dx.doi.org/10.1093/jnci/dji286

[24] Smith, E., Frierson, H., Mills, S., Boyd, J.C. and Theodorescu, D. (2002) Gleason Scores of Prostate Biopsy and Radical Prostatectomy Specimens over the Past 10 Years. Is There Evidence for Systematic Upgrading? Cancer, 94, 22822287. http://dx.doi.org/10.1002/cncr.10457 
[25] Epstein, J. (2000) Gleason Score 2-4 Adenocarcinoma of the Prostate on Needle Biopsy: A Diagnosis that Should Not Be Made. American Journal of Surgical Pathology, 24, 477-478. http://dx.doi.org/10.1097/00000478-200004000-00001

[26] Korman, H., Lanni Jr., T., Shah, C., Parslow, J., Tull, J., Ghilezan, M., et al. (2013) Impact of a Prostate Multidisciplinary Clinic Program on Patient Treatment Decisions and on Adherence to NCCN Guidelines: The William Beaumont Hospital Experience. American Journal of Clinical Oncology, 36, 121-125.

http://dx.doi.org/10.1097/COC.0b013e318243708f 
Scientific Research Publishing (SCIRP) is one of the largest Open Access journal publishers. It is currently publishing more than 200 open access, online, peer-reviewed journals covering a wide range of academic disciplines. SCIRP serves the worldwide academic communities and contributes to the progress and application of science with its publication.

Other selected journals from SCIRP are listed as below. Submit your manuscript to us via either submit@scirp.org or Online Submission Portal.
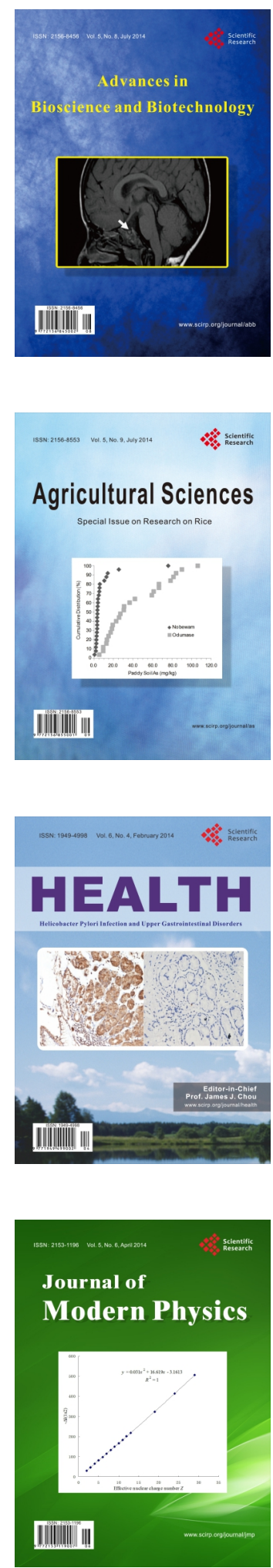
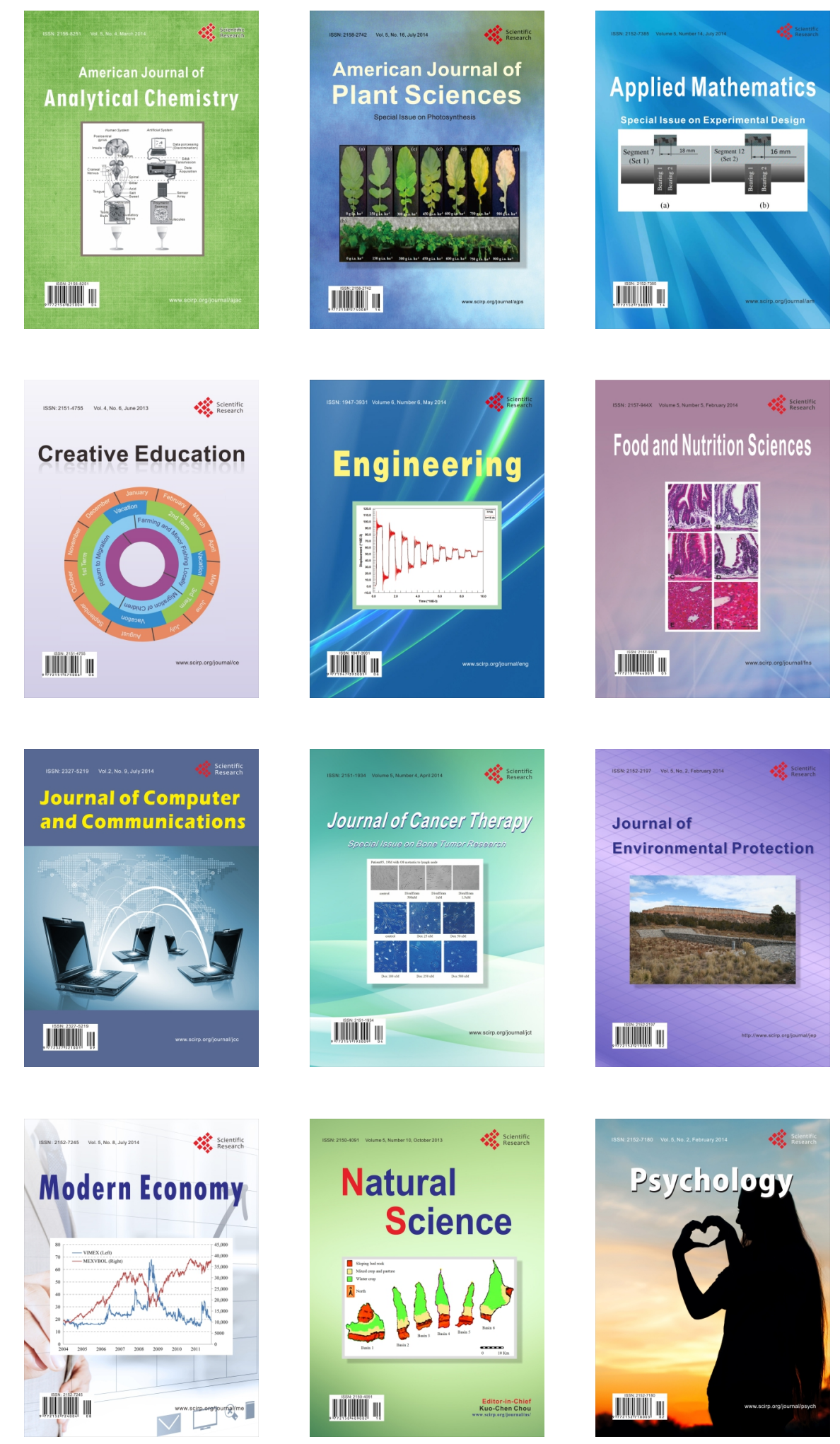